\title{
MONSTRUOS FANTÁSTICOS EN LA LITERATURA COSTARRICENSE
}

\author{
José Ricardo Chaves
}

\section{(9) $(\Theta \Theta$}

Esta obra está bajo una licencia Creative Commons

Reconocimiento-No Comercial-Sin Obra Derivada 



\title{
MONSTRUOS FANTÁSTICOS EN LA LITERATURA COSTARRICENSE
}

\author{
FANTASTIC MONSTERS IN THE COSTARICAN LITERATURE
}

\section{José Ricardo Chaves}

\begin{abstract}
RESUMEN
A partir del concepto de hibridez como base de lo monstruoso, se hace una revisión cronológica de algunas apariciones teratológicas en la literatura costarricense, desde sus inicios a fines del siglo XIX y principios del XX, con la incorporación de seres de la mitología popular (del tipo de la Segua, la Llorona o el Cadejos) o de la mitología clásica (la sirena), en autores como Manuel Argüello Mora o Joaquín García Monge, pasando por reapropiaciones góticas como en Jenaro Cardona, hasta las formas más modernas, como las de Alfredo Cardona Peña, Eunice Odio, Myriam Bustos y Rafael Ángel Herra.

Palabras clave: monstruos, metamorfosis, hibridez, literatura costarricense, literatura fantástica.
\end{abstract}

\begin{abstract}
Starting from the cathegory of Hybridity as a basis for the Monstrous, I trace a chronological revision of some teratological appearances in the Costarican literature. I begin with authors from the end of the XIXth century and the first decades of the XXth (Argüello Mora, García Monge), incorporating beings from the local folklore and the classical mythology (the Mermaid); going through gothic reappropriations as in Jenaro Cardona, arriving to more modern forms as in Cardona Peña, Eunice Odio, Myriam Bustos and Rafael Ángel Herra, in the second half of the XXth century. Key words: monsters, metamorphosis, hybridity, Costarican literature, fantastic literature.
\end{abstract}

En la conformación del repertorio de la literatura fantástica a partir del siglo XIX en Europa, una de las figuras privilegiadas fue la del monstruo, humano o no, que a lo largo de esa centuria no cesó de generar nombres emblemáticos, como el jorobado de Notre Dame, la criatura de Frankenstein o Drácula el vampiro. Algunos de estos monstruos son únicos, otros son parte de una especie. Si como especie pueden preceder al personaje literario gracias al

Dr. José Ricardo Chaves. Investigador del Centro de Poética del Instituto de Investigaciones Filológicas de la UNAM. México.

Correo electrónico: richavespa@gmail.com

Recepción: 23- 04- 2015

Aceptación: 19- 06- 2015 
folclor, su consolidación en la cultura moderna supuso un texto escrito que los llevara al apogeo mediante una estrategia adecuada. El monstruo se caracteriza por su hibridez, por la ausencia o presencia de ciertos rasgos pertenecientes a órdenes distintos (animal/humano, masculino/ femenino, animal/vegetal, vida/muerte, etc.) o la mezcla inapropiada de varios de ellos, lo que genera una carencia o un exceso y lo ubica fuera de un canon estético previo, o mejor, como lo opuesto del arquetipo aceptado canónicamente. Para efectos inmediatos, coincido con el punto de vista de Rafael Angel Herra en su libro Lo monstruoso y lo bello, cuando dice que "el lector no deberá esperar aquí una definición formal de monstruo, sino, a lo más, descripciones y presunciones" (Herra, 1988, p. 24). A partir de la característica básica de la hibridez, se presentarán las descripciones comentadas de los monstruos creados por varios autores costarricenses. Hay que tener en cuenta que no todos los monstruos son entes fantásticos ni todos estos son monstruosos. Por ejemplo, los fantasmas tan solicitados por dichas tramas, no son monstruos. Tampoco el diablo en sí mismo es uno de ellos, aunque algunos de sus rasgos suelen habitarlos, como la fealdad, la crueldad o la astucia.

Con el auge de los estudios mitológicos y religiosos que el romanticismo primero, y el positivismo después, impulsaron (aunque con perspectivas muy diferentes), buena parte de los acervos orales en donde solían habitar los monstruos comenzaron a ponerse por escrito y así se volvieron literatura, dirigida en sus inicios paradójica y mayormente a un público infantil. Es el caso de los hermanos Grimm, o de Andersen o de Perrault. Se asiste así a un bagaje mítico de tradición oral (la leyenda y el cuento) que se transforma en texto escrito, muchas veces suavizado por las nuevas consideraciones morales, en lo que algunos han llamado la "literaturización del mito". Todo esto apuntala la teoría de los orígenes populares, y específicamente orales, del relato fantástico, como bien lo señalaba ya Adolfo Bioy Casares en el prólogo de la famosa Antología de literatura fantástica de 1940: "Viejas como el miedo, las ficciones fantásticas son anteriores a las letras" (1976, p. 7). En la literatura, paulatinamente el mito se torna en "tema", desde un cierto enfoque narrativo y argumental específico, en un texto literario concreto, que se vuelve luego susceptible de nuevas lecturas, esto es, de ser reformulado por otros autores en textos diferentes, y que van conformando así tradiciones y cadenas temáticas textuales, alimentadas con los desplazamientos semánticos de dicho tema, con repeticiones innovadoras a partir de un cierto perfil reconocible, algo ya señalado en el área tematológica de los estudios de literatura comparada. Esta posibilidad de reorientar los contenidos y estructuras de los textos iniciales puede llevar a una modificación del género literario, de tonos y registros, incluida la estrategia muy moderna de desmitificación o secularización de los núcleos numinosos originales. Al mismo tiempo, en una Europa decimonona que alimentaba los discursos nacionalistas, esas colecciones se convirtieron en alimento de las construcciones identitarias colectivas o nacionalidades.

Estos procesos culturales no fueron ajenos a la experiencia hispanoamericana, aunque se dieron en contextos distintos, pues aquí no siempre existían en cada país corpus textuales de larga data sobre los cuales pudieran insertarse, como en Europa, sino que a veces más bien facilitaron la generación de un corpus textual fundacional para una comunidad nacional específica, como en el caso de Costa Rica. Así, la puesta por escrito de leyendas coloniales, en algunos casos con antecedentes prehispánicos, fue una de las formas en que se impulsó el surgimiento de literaturas nacionales y regionales en español. Tanto el romanticismo como el positivismo liberal favorecieron este tipo de estrategias literarias en nuestros países, en busca de la generación o robustecimiento de literaturas nacionales, acorde con los proyectos políticos independentistas. 
Como resultado, la escritura de inspiración histórica, ya fuera en cuento, novela, leyenda o crónica, floreció en el siglo XIX y siguió en el siglo XX, aunque ya con otros rasgos. Cada país puede presentar su nómina de autores pioneros, como Vicente Riva Palacio, Justo Sierra o Artemio de Valle-Arizpe en México; o Ricardo Palma en Perú; o Manuel Argüello Mora, Manuel de Jesús Jiménez, Anastasio Alfaro o Ricardo Fernández Guardia en Costa Rica. Estas primeras recolecciones y recreaciones hispanoamericanas, a diferencia de las de sus colegas europeos, que se apoyaban grandemente en la tradición oral y que dirigían sus producciones en gran parte a los niños, suelen alimentarse más bien de los archivos coloniales, tienen una visión historicista y secular para adultos, y suelen dejar de lado los elementos fantásticos, propios, a su juicio, de la superstición y la ignorancia.

Coexistiendo con estas primeras recolecciones históricas del siglo XIX y de principios del XX, que solían dejar de lado lo fantástico, en América Latina continuaba viva la tradición hablada, sobre todo en contexto rural, con una gran variedad de figuras de mitología popular, verdaderos símbolos coloniales de mestizaje cultural, pues algunas de ellas suponen un trasfondo prehispánico (por ejemplo, la Llorona, la Segua, la Tule Vieja, para el caso costarricense y mesoamericano en general), con un influjo europeo posterior que le añadió nuevas formas y rasgos (y dejaba de lado otros, por ejemplo el politeísmo original). Este panteón popular, aunque cristianizado, continuó vehiculando ciertos contenidos paganos, y también fue sometido a ese proceso de "literaturización del mito" ya señalado, por el lado de lo fantástico.

Durante mucho tiempo se ciñó el surgimiento de la literatura fantástica hispanoamericana sobre todo a los inicios del siglo XX, a partir del modernismo, y no ha sido hasta las últimas décadas que han comenzado a investigarse con más detalle sus manifestaciones previas en el siglo XIX, por ejemplo para los casos de México y Argentina. Esto ha llevado a un replanteamiento del fenómeno fantástico latinoamericano, que ha ganado presencia en tiempo y cantidad. Un rasgo distintivo suyo, con respecto a la experiencia europea, es que surgió, no tanto de antecedentes románticos, sino más bien positivistas y realistas, en que el fenómeno fantástico es visto como algo excepcional y que debe ser explicado (o descalificado) por causas naturales, como el sueño, la alucinación, la embriaguez, etc.

\section{Inicios fantásticos con la Sirena y la Llorona}

Uno de los textos iniciales de la literatura fantástica costarricense es "La poza de la Sirena", escrito por Manuel Argüello Mora y publicado bajo el seudónimo de "Sirio" en la revista Costa Rica Ilustrada, en 1887 o 1888. Como se recordará, Argüello, sobrino del expresidente Juan Rafael Mora, es considerado como uno, si no el primero, de los escritores costarricenses, con una obra de corte histórico, aunque muy narrativizada, lo que le brinda un gran encanto. Esta es una de las razones por la que su cuento fantástico cobra particular interés, debido a su rareza. El título se debe al lugar donde ocurren los eventos fundamentales de la trama, y al encuentro del personaje masculino, Arturo, con una sirena que aparece ahí anualmente: 
Quiero resaltar varios rasgos: primero, la ubicación nacional y conocida del escenario del hecho fantástico, un paraje “cerca de la confluencia de los ríos Virilla y Tiribí”, lo que permite de entrada un mayor acercamiento del lector costarricense; segundo, el carácter cíclico (anual) de la "aparición” de la sirena, en la noche del Día de la Asunción, con lo que la sirena, calificada de inofensiva, queda asociada con la Virgen María (la Gran Madre), lo que refuerza su carácter benéfico, como se verá en el desarrollo de la historia; tercero, la descripción del cuerpo de la sirena, que une lo humano con el pez, pero además, con la tradición clásica grecolatina al mencionar a Venus, si es que no bastara la referencia a las sirenas clásicas del tipo de Homero y Ovidio. En resumen, tenemos un ambiente costarricense y un ente fantástico que reúne, no solo lo ictiforme y lo humano, el agua y la tierra, sino también lo cristiano y lo pagano, lo nacional y la tradición europea.

Pese a su relativo bienestar material, el personaje de Arturo se muestra insatisfecho, su hogar y su familia no lo llenan del todo, y anhela el poder, la riqueza y el reconocimiento social. La sirena tiene la capacidad de cumplirle su deseo pero advierte que nunca tendrá otra cosa que lo otorgado en esa ocasión. Arturo obtiene lo solicitado, dinero, poder, fama, pero no contaba con las posteriores enfermedad y muerte de su pequeña hija, inevitables pese al fastuoso ambiente. La pesadumbre lo invade y al agosto siguiente, en la próxima aparición de la sirena, él la interpela e incluso la maldice, pues "Arturo solo vio en aquella aparición un ser sobrenatural impotente y engañoso, puesto que no pudo o no quiso conservarle su hija" (Argüello-Mora, 2012, p. 29). Pese a la ofensiva de Arturo, la sirena continúa "con su bello semblante siempre sereno y lleno de bondad" (Argüello-Mora, 2012, p. 29), y tras advertirle que aprenda la lección de su vanidad, revierte lo acontecido y entonces Arturo despierta como de un sueño y se encuentra con su hija y su esposa, para su gran alegría. La causa de tales fantasías se racionaliza con unas "pastillas de hastchiz" que Arturo había tomado previamente por recomendación médica. El milagro acontecido busca ser explicado por una causa material, como corresponde a la lógica de lo fantástico realista, del que forma parte este cuento. De paso nótese el cambio cultural dado con los años y la historicidad del mal, pues lo que hoy se considera como una droga maligna, en aquellos tiempos de Manuel Argüello era apenas un tranquilizante médico o un estímulo estético, si se seguía el ejemplo de Baudelaire.

Al año siguiente de haber publicado "La poza de la sirena", en 1899 Argüello saca su libro Costa Rica Pintoresca. Sus leyendas y tradiciones, en el que aparece un relato que viene a colación para nuestro asunto, titulado "La Llorona", por el que hace su aparición literaria este espectro regional en la literatura costarricense, pues aparece también en otras literaturas latinoamericanas. Es interesante que el mismo autor escriba en tan breve tiempo dos textos alusivos a seres fantásticos femeninos, la sirena ya vista, y ahora una fantasma local, la Llorona. Aclaro en este sentido que no considero a la Llorona como un monstruo (como sí lo son la Segua o el Cadejos, que, en tanto híbridos, conjuntan rasgos disímbolos que asustan), pues pertenece más bien al linaje de los fantasmas, de las ánimas en pena, y no hay en ella alguna hibridez monstruosa. Si asusta, es por su descuido personal debido a la pena que sufre y por sus gritos y su llanto, no porque sea horrible físicamente. Argüello acogió a este fantasma llorón en su escritura, muy distinto de la sirena, descrita por él como buena y cercana a la Virgen y a Venus. Más allá de esta valoración, lo cierto es que el autor no se conformó con la sirena clásica, a pesar de que la sometió al mestizaje cultural para que surgiera una sirena criolla, sino que requirió de un mito local, y entonces tomó a la Llorona como personaje. 
Curiosamente ambas figuras están vinculadas con el agua, la fuente, el río, la poza, y con la fertilidad femenina que ello supone, triunfante con la sirena, maldita con la Llorona. Unos años antes, en 1894, Ricardo Fernández Guardia había publicado su polémico libro Hojarasca, en el que aparece su "cuento neogriego", según lo llama, titulado "El manantial", en el que, si bien no hay sirenas, sí hay una ondina "con ojos verdes como las algas y blanca como un lirio" (Fernández-Guardia, 2004, p. 12). Esta otra mujer acuática posee de suyo toda una cadena de apariciones literarias, por lo menos desde el romanticismo.

\title{
2. De la sirena transexual al Cadejos manso, pasando por la Llorona "idiática"
}

Lo que en Argüello aparecía separado (por un lado la sirena; por el otro la Llorona), aparecerá junto en un texto de la misma fecha (1899, en La Prensa Libre), escrito por un joven de 18 años, Joaquín García Monge, titulado “Del Pueblo (leyendas)”. Un abuelo reunido con su familia cuenta cuentos de miedo en la noche, y los tres que narra son sobre la Sirena, la Llorona y el Cadejos. Aquí se reúnen en un solo texto seres de variada mitología en un medio claramente costarricense, marcado no solo por la descripción geográfica sino por el lenguaje vernacular de sus personajes, como corresponde a la expresión costumbrista de la época. Esta reapropiación local del mito que efectúa García Monge incluye una modificación lingüística, la del nombre, que en lenguaje campesino se pronuncia como la "Sirenia", con lo que el idioma local "monstrifica" o deforma el español castizo, y la cual es descrita así: "Milagro patente es el de ese animal que vivía en la mar llamado La Sirenia, y que se aparecía al prójimo en forma de mujer de la centurap'arriba y de los cuadriles p'abajo lo mismo que un peje" (García-Monge, 2009, p. 65).

Más llamativo que esta descripción final es su origen, pues en el relato esa sirena es resultado de una maldición de Semana Santa sobre un joven,

\begin{abstract}
un muchacho muy guapo, mentado Nicolás, alto y derechito como una mata de plátano y todo él de buena hechura. Tenía la rutina de irse a bañar todos los días del mundo a la orilla de la playa, chingo en pelota; bien agarrao de un bejuco esperaba que las olas llegaran en brinquitos y lo envolvieran en espuma (García-Monge, 2009, p. 65)
\end{abstract}

Nótese en esta descripción el énfasis en la belleza del joven, así como su carácter despreocupado y quizá narcisista, así como de una pasividad casi femenina ante las olas del mar. El sacerdote del lugar lo amenaza con maldecirlo si se baña en día santo, en pez se ha de volver, y el joven lo desobedece:

\footnotetext{
Dicho y hecho, apeniticas se metió playa adentro, cogió la figura que tiene, un Jueves Santo por más señas [...] De allí p'alante la Sirenia es un espíritu y se relaciona con el Pizuicas. Siempre está nadando alrededor de la irla y cuando sabe que hay algún muerto o algún novio en su casa, manda a pedir una canoa y asiste a la vela o al casamiento (García-Monge, 2009, p. 66)
}

Es así como ese joven de buena hechura y derechito como mata de plátano termina convertido en sirenia por castigo divino, con cuerpo femenino "de cristiano y de peje". Pareciera que este "sireno" garciamongesco es el primer caso de personaje transexual de la literatura costarricense. En este sentido es muy distinto de la sirena de Argüello, modosita y santa en su virginidad desde siempre y para siempre, pues la sirenia fue hombre alguna vez, no solo como especie sino también como género. Además, nótense algunos añadidos valiosos: su vinculación diabólica (el Pizuicas), lo mismo que vínculos con la muerte y el matrimonio. Así, sus connotaciones míticas aparecen más matizadas. 
Después el abuelo se refiere a la Llorona, a la que vio en alguna ocasión, sentada en un pedrón "con la macolla de pelos que le llegaba a los cuadriles" (García-Monge, 2009, p. 68). Es tonto asustarse de ella, pues "la Llorona no hace nada, sólo piensa en su chiquilín" (GarcíaMonge, 2009, p. 68). Según cuenta el viejo, Dios la condenó por ahogar a su hijo a buscarlo hasta el día del Juicio, y hasta acrecienta su pena mediante el engaño visual pues "muchas veces (Dios) pa burlar sus deseos se lo da a ver en el lomo de la corriente y la Llorona se tira tras del. Pero ¿pa qué?... Eso nunca lo conseguirá... A veces se vuelve idiática y se figura velo" (García-Monge, 2009, p. 68). En esta presentación, la Llorona adquiere un matiz trágico, como Sísifo o el rey Midas, cuyo objetivo nunca se cumple y ha de volver a empezar una y otra vez, hasta el día del Juicio, como bien se señala.

El tercero y último personaje mítico abordado por el abuelo cuentacuentos es nada menos que el Cadejos, el que sí entra sin problema en la categoría de monstruo dada su hibridación: "Tiene todas las trazas de un cabro, el pelo tieso y puntiagudo como espinas, unos ojos que relumbran como candela, un hocico que le chasquea y al andar parece que estuviera encasquillao; [...] tiene un pellejo que ni pa qué decir -cuando no l'entra la bala" (García-Monge, 2009, p. 69). Pese a esta descripción tan material, el Cadejos es "espíritu y de los malos, pero muy amigo del hombre. ¡A saber desde qué tierras viene! Ya lo ven tan feo, y no hace daño [...] los que lo han encontrao [...] hasta que se ponen irizos contando que, joh animal más horrible!" (García-Monge, 2009, p. 69). Primero se afirma que es un espíritu malo, y luego que no hace daño; su origen es un misterio, y la fealdad su rasgo dominante.

De esta forma García Monge reunió en un solo texto una figura clásica, la sirena (en variante transexual), y dos criollas, la trágica Llorona y el horrible Cadejos, ambos inofensivos, en un relato que se reclama como "del pueblo", no solo por sus temas y su fusión cultural sino sobre todo por el lenguaje costumbrista que adopta, todo ello con la idea de definir una identidad nacional. La sirena siguió vigente en la literatura nacional, como lo muestran algunos textos de Carlos Gagini, sobre todo su novela de 1918 titulada La Sirena (Cf. Castillo-Víquez, 2004), pero dado que ahí el tratamiento es figurado, no me referiré a este texto realista sentimental y no fantástico. Por su parte, los espectros populares seguirían su colonización del mundo literario, alcanzando la cima, a mi juicio, en una serie de poemas de Carlos Luis Sáenz, de 1944, titulada "4 motivos del folklore costarricense", dedicados al Cadejos, la Llorona, la Carreta sin Bueyes y la Cegua, en que se les convoca sin ironía.

\section{De Cardona a Cardona Peña o del esqueleto asesino al onoco}

Además de las versiones localistas de la sirena de Argüello y García Monge, en que la mujer pez convive con la Llorona y el Cadejos, está la vertiente cosmopolita de lo fantástico, representada por el texto de 1929 de Jenaro Cardona llamado "La caja del doctor (Cuento macabro)". El autor era reconocido por entonces por sus dos novelas realistas con algo de sentimental, sobre todo La esfinge del sendero, de 1917, no tanto El primo, de 1905, que algunos consideran la primera novela nacional, y no, como hacen otros, que le dan ese lugar a El moto, de Joaquín García Monge, que es más bien una nouvelle o novela corta de 1900. A diferencia de los otros dos autores, Cardona plantea de forma excepcional en su escritura una historia, no solo fantástica, sino además gótica, que él prefiere llamar "macabra", como lo señala el subtítulo. Su principal personaje, el Dr. Milianikoff, es nacido en Suiza de padre ruso y madre polaca, y es una mezcla de reconocido científico y de estudioso de ciertas ramas de lo oculto: “También 
había cultivado como simple deporte el magnetismo, y ¡cosa rara!, a pesar de ser un convencido discípulo de Darwin, había espigado en los campos del espiritismo, llevado sin duda por el afán especulativo que sentía por todas las ciencias" (Cardona, 2012, p. 39). Tanto era su talento al respecto que, de haberlo querido, "el doctor Milianikoff habría sido el primer hipnotista del siglo" (Cardona, 2012, p. 39).

Huyendo de un pasado incierto, el doctor deja Europa y se establece en Costa Rica, sí, pero no en una Costa Rica campirana, como las elaboradas por Argüello y García Monge, sino una misteriosa, emblematizada en términos de espacio con el Museo Nacional, lugar donde él trabaja y donde ocurre la acción fantástica del relato; un museo conocido como "La Casa del Laberinto", por la calle en que estaba ubicado, la actual calle tercera, y que "era tenida como lugar propicio a apariciones de duendes y de fantasmas, algo así como un fatídico aquelarre" (Cardona, 2012, p. 36). Cardona no teme recurrir a una trama internacional, ni a triquiñuelas grotescas de la tradición europea para su historia josefina, y lo hace muy bien. Milianikoff mantiene un secreto representado por la caja que siempre carga, como si fuera maleta o una pesada cadena, y que se manifestará de manera fantástica al final del cuento, cuando el pasado reprimido en esa caja salga a la luz de forma siniestra y fatal, y el esqueleto de su esposa por él asesinada guardado ahí retorne a la vida para a su vez asesinarlo a él, en pleno museo de noche, como si fuera una víctima más del Minotauro en la Casa del Laberinto. He aquí parte de ese terrible momento:

\footnotetext{
[...] un esqueleto humano, que por su contextura parecía de mujer joven, se irguió siniestro, amenazador, alzando la seca armazón de sus brazos, como en un conjuro de soberano castigo. De las cuencas vacías emanaba una luz fosfórica, y los dientes, blanquísimos, brillaban en la oscuridad con esa risa desnuda que no acaba nunca, porque es una mueca eterna (Cardona, 2012, p. 43)
}

Al día siguiente, son encontrados el cadáver del doctor junto a un esqueleto: "La cabeza del doctor presentaba una profunda herida en el parietal derecho, por la cual podía verse, entre coágulos sanguinolentos, una porción de la masa encefálica" (Cardona, 2012, p. 45). Por otra parte, "el esqueleto mantenía entre los huesos de la mano derecha, una maza de jade, primorosamente labrada, simulando una calavera, y manchada de sangre" (Cardona, 2012, p. 45). Pese a todo este horror grotesco, el esqueleto redivivo de Cardona no es un monstruo en la medida en que no posee una fealdad híbrida, está más cerca de la pureza simbólica del fantasma vengador, pero sí posee en común con aquél su capacidad para causar destrucción y temor. Híbrido es más bien el ambiente del museo en el que resucitará el esqueleto, con "grandes vitrinas que contenían millares de ejemplares de nuestra fauna” (Cardona, 2012, p. 35), incluida una enorme cabeza de alce que tendrá después un lugar importante en la historia; también se aprecia "la cerámica que nos han legado nuestros aborígenes, constante de extensas y variadas colecciones de piezas"; "en otras salas, sobre tarimas y estantes, podía apreciarse una muchedumbre de objetos de piedra, ídolos, metates, mesas lindamente ornamentadas, piedras de sacrificios, trípodes, objetos de jade, hachuelas, mazas, etc." (Cardona, 2012, p. 36). Todo lo anterior lleva a ver en Cardona una especie de cosmopolitización de lo fantástico, en un texto que fue ave rara en su obra, y que seguirá vigente en su propio linaje familiar cuando, muchos años después, su nieto, Alfredo Cardona Peña, retome tales afanes por lo fantástico en su propia obra literaria.

Cardona Peña se consideraba a sí mismo ante todo como un poeta, y así es recordado en buena medida en la historia literaria, pero visto en perspectiva pienso que tiene un papel más importante y renovador como autor de literatura fantástica y de ciencia ficción, no solo en México y Costa Rica, países en los que publicó su obra de narrativa fantástica, sino en toda América 
Latina. De hecho, Rafael Llopis, el estudioso español, en su famoso libro Historia natural de los cuentos de miedo (1974), lo incluye entre sus cultores latinoamericanos, y Edmundo Valadés, el cuentista mexicano, lo llama "fabulador nato", "notabilísimo ingenio entre los narradores de lo fantástico, y en Hispanoamérica, como uno de los más interesantes en el género de la ciencia ficción" (Cardona-Peña, 1980, p. 9). En los últimos años, en México se lo ha tomado en cuenta como un cultivador importante de la ciencia ficción y se le incluye en antologías.

Como su abuelo Jenaro, del que se sentía orgulloso sobre todo por haber escrito La esfinge del sendero, Cardona Peña cultivó también una escritura fantástica cosmopolita, universal, que abrevó en múltiples fuentes sin rechazar por principio el terruño pero tampoco sin cultivarlo de manera especial, diversidad de fuentes de la que él mismo da cuenta en su texto "El brebaje" (1972), en el que, entre una larga lista, menciona como ingredientes de su receta estética "crótalos de Quiroga; dos ajos de Quevedo; naves de Bradbury; gotas de Flaubert; laberintos de Borges; miedos de Lovecraft, etc., etc., sin olvidar, naturalmente, jugo de sauces de Blackwood, uñas del hijito de Mary Shelley, deducciones de Agatha Christie" (Cardona-Peña, 2012, p. 223).

Cardona Peña pertenece a una generación nacida a finales de los diez y principios de los veinte del siglo pasado, que comenzó a cultivar de una forma moderna el género fantástico, más distanciada de los efectos de sentido y más dirigida a la forma y la expresión, y en la que están otros autores como el guatemalteco Augusto Monterroso y el mexicano Juan José Arreola. Monterroso señala a la Antología de la literatura fantástica compilada por Jorge Luis Borges, Silvina Ocampo y Adolfo Bioy Casares, y publicada en 1940 en Buenos Aires, como el evento literario decisivo para modificar la percepción general de lo fantástico en la literatura latinoamericana de la época:

\begin{abstract}
Poner como hito esa Antología admirable, sin embargo, no es tan arbitrario en el caso de México como podría parecerlo en un primer momento. Yo -y sólo me pongo como testigo- pertenezco a la misma generación de narradores a la que pertenece Juan José Arreola, la cual -junto con otros escritores centroamericanos y sudamericanos que por entonces vivían y publicaban en México sus primeros trabajos, impresionados todos por ese libro, por las obras de Franz Kafka, que en esos años cuarenta empezaban a conocerse en español y, no faltaría más, por la literatura de Borges- comenzó a liberarse del tradicional apego a los temas literarios realistas y circunscritos a lo autóctono, a los problemas de los campesinos y a la Revolución para ir al encuentro de espacios más complejos en el mundo de la ciudad y de la imaginación [...] Por experiencia personal, pues, tengo el convencimiento de que aquella Antología, junto a los cuentos cortos de Kafka, más que a sus novelas, fue el detonador de un profundo interés en el camino que abría la literatura fantástica como forma de expresión muy antigua y muy nueva, y en la que uno podía aventurarse como en un viaje a lo desconocido (Monterroso, 1991, pp. 180-181)
\end{abstract}

Entre esos escritores centroamericanos mencionados por Monterroso estaba Cardona Peña. Su obra fantástica y de ciencia ficción incluye tres títulos principales, dos publicados en México, Cuentos de magia, de misterio y de horror (1966) y Los ojos del cíclope (1980), y uno en Costa Rica, Fábula contada (1972). Su último libro de 1980 está dividido en cuatro secciones, "Ciencia ficción", "Vampiros, demonios y fantasmas", "Miscelánea fantástica" y "Confeti erótico". En la segunda sección incluye un breve texto titulado "El onoco", que es básicamente una viñeta descriptiva de un animal imaginario. Recoge algunas descripciones que hablan de cincuenta extremidades "como pelos con uñas" y de noventa y dos ojos, para concluir que "el onoco tiene forma circular, o sea, que es como una rueda con muchas patas y ojos, y cuyo tamaño alcanza los dos metros de diámetro, más o menos [...] El onoco rueda sobre sí mismo, y está comprobado que emite gemidos de cachorro" (Cardona-Peña, 1980, p. 89).

Prosigue Cardona Peña con una caracterización del onoco que me recuerda, con las variaciones del caso, el tono rural y melancólico de la Llorona: "No aparece sino en los sitios 
más oscuros de caminos y follajes, de preferencia cercanos a los ríos, y su cuerpo es débilmente luminoso, dejando al hacerse invisible una mancha lunar sobre la tierra, algo así como un talco fosforescente que luego, a su vez, desaparece" (1980, p. 89). Después de todo, la Llorona es un mito compartido por México y Costa Rica, los dos países queridos de Cardona Peña, y tal vez su llanto sepulcral influyó en el gemido de cachorro del onoco, y en su cercanía con el agua. Ante la descripción circular y rodante del onoco, también podría pensarse en otro espectro colonial, en la Carreta sin Bueyes, aunque por su carácter mecánico y artificial, resulta más orgánico que se lo vincule con la Llorona.

Sin duda, de Cardona a Cardona Peña se puede detectar en Costa Rica un linaje literario de expresión fantástica, solitaria aunque valiosa y atrevida en el abuelo, múltiple y genérica en el nieto, con quien adquirió gran diversidad temática y expresiva, con una casi permanente ironía en el tratamiento que no siempre beneficia a la historia, o que lo encasilla en una cierta perspectiva que le impide explorar otras posibilidades, lo que se compensa con una gran diversidad de temas y personajes (fantasmas, vampiros, robots, naves espaciales, demonios).

\section{Metamorfosis de Franz Kafka, Eunice Odio y Myriam Bustos}

Transcribí antes el testimonio de Augusto Monterroso sobre la importancia que, a su juicio, ejercieron los relatos de Kafka y la Antología de Borges, Bioy y Ocampo sobre los nuevos escritores latinoamericanos interesados en desarrollar una literatura fantástica, desde la década de los cuarenta. Hay que tener en cuenta que desde 1925 existía una traducción de La metamorfosis publicada en Madrid por la Revista de Occidente, misma que se republicó en 1945. En América Latina, en 1938 apareció en Buenos Aires, por la editorial Losada, una traducción de ese texto, atribuida entonces equivocadamente a Jorge Luis Borges, quien, si bien no tradujo ese relato en especial, como reconocería muchos años después, sí tradujo otros de esa misma colección. De hecho, Kafka está incluido en su famosa Antología de 1940. Además, en la enumeración de argumentos fantásticos que hace Bioy en su prólogo menciona la metamorfosis como uno de ellos, y pone como ejemplo justamente La transformación de Kafka (traducida también como La metamorfosis) y "Ser polvo", del argentino Santiago Dabove.

Con esto queda claro que la lectura de Kafka fue una de las novedades importantes en el panorama literario con aspiraciones fantásticas, no solo entre autores como Monterroso, Arreola y Cardona Peña, sino también en una escritora afiliable a esa "generación" por edad y por lugar donde vivía (México), Eunice Odio, recordada sobre todo como poeta, pero autora también de dos relatos fantásticos, "Había una vez un hombre", publicado en la revista El Cuento en 1970 (aunque fue escrito en 1965), y "El rastro de la mariposa", publicado en 1968 en la revista venezolana Zona Franca. En ambos relatos el asunto básico es justamente la transformación de sus personajes en insectos, específicamente en mariposas. Si bien Eunice retoma el tópico de la metamorfosis, tal vez inspirada en Kafka, lo hace de una manera muy distinta, pues en su caso dicha transformación en insecto tiene un carácter ascendente, simbólico, diríase incluso alquímico, y conlleva un cierto despertar espiritual, a diferencia del insecto rastrero del escritor checo (que algunos identifican con la cucaracha, aunque esto no se diga en el texto), que alude más bien a una degradación y limitación creciente. Mientras que los personajes mariposa de Odio se mueven en una dirección vertical más allá de la copa del árbol, el de Kafka se arrastra por la tierra esperando algo peor.

El mero cambio de un humano en insecto no sería monstruoso por el resultado en sí (a no ser que el tamaño se magnificara), de hecho a diario vemos montones de bichos y no 
pensamos que son monstruos ni asustan a nadie; lo teratológico estriba en ese caso en el proceso que lleva de un estado a otro, y que el sujeto transformado fuera originalmente humano. El cuento de Kafka inicia con el humano ya convertido en insecto, lo que parece no espantar mucho a los personajes, incluido el mutante. En cambio, los dos cuentos de Eunice Odio son la crónica de la transformación en algo superior, trascendente, con un simbolismo alquímico explícito en "El rastro de la mariposa". Mientras que en Franz Kafka la transformación es degradación, en Eunice Odio es trascendencia metafísica.

En ambos autores hay una escritura fantástica inmersa en la descripción doméstica, los ambientes, personajes y situaciones son cotidianos, excepto por el detalle de que uno de los personajes se despertó convertido en alimaña y otros dos están en vías de volar como mariposas alquímicas, y todo sigue como si nada raro pasara. En el primer cuento de Eunice, el personaje principal es un pepenador, un recogedor y separador de basura, que, debido a su bondad, finalmente, en medio de su pobreza y dolor, alcanza una metamorfosis física en mariposa, como alegoría de hallazgo espiritual. Poco a poco percibe cambios en su cuerpo: "Tenía la cabeza rígida y brillante, y el cuerpo vuelto partes desiguales, diferentes a las de siempre" (Odio, 1996, p. 267); "se le había desprendido un gran trozo de piel" (p. 269); "tenía los dedos de ambas manos, llenos de un polvo azul claro... azul celeste..." (p. 270), como las alas de la mariposa en que finalmente se convertirá. En su transformación, llega un momento en que "caminó o, más bien se arrastró a pasitos, como las hormigas o las... No se atrevió a nombrarlas...” (p. 275). La última parte del proceso es interesante porque tiene que ver con la lengua como órgano físico pero también como verbo: "No podía articular palabra. Era su lengua la que no le obedecía. Echó hacia atrás la cabeza reclinándola en el asiento... Era la lengua... Se tocaba con ella el paladar informe, y la sentía llena de espinitas finas y voraces..." (p. 275).

En el caso de "El rastro de la mariposa" los personajes no son de extracción popular, sino educados e incluso sofisticados en sus saberes, pues uno es científico que busca crear vida de manera artificial; afirma que "dejé la alquimia cuando había llegado al penúltimo escalón, porque no me interesaba su fin último sino sus medios... Y porque llegó a fascinarme el movimiento de todo ser vivo" (Odio, 1996, p. 285); y el otro es un pintor practicante de budismo Zen:

Durante dos años noté que cuanto más me internaba en la senda del koan, tanto más me ligaba al goce estético en sí, en vez de desligarme de él... hasta que me fundí con él en forma tal, que hemos llegado a ser una y la misma cosa... Yo... Un estado del alma, mientras sobre la tela hago nacer la animación que nunca cesa [...] El misterio del koan no me dio el Nirvana, pero sí el centro de mi equilibrio en la Tierra (Odio, 1996, p. 283)

Y como previendo su futuro, exclama: "Quiero ser el prójimo de una libélula” (p. 283).

Libélula, mariposa... se trata de un insecto leve y maravilloso, para nada suscitador de ascos y rechazos, y que apunta a una ingrávida estructura casi vacía. He aquí parte de la transformación:

\footnotetext{
El hueso ilíaco se le había aligerado tanto, que tenía la delgadez de una oblea. Poco después quedó disuelto junto con todo su esqueleto que se diseminó por el cuarto. Ahora se sintió ligero como el día, acariciado dentro de la carne. Su traje, que ya no contenía nada, cayó vacío al suelo. Trató de verse por fuera... No se veía nada. Se miró por dentro. Vio un agujero luminoso que era él. (Odio, 1996, p. 290)
}

Al final del texto, por distintas vías, ambos amigos consiguen su ideal de transmutación, uno acudiendo a las formas científicas (aunque violentas), y el otro, el artista, por medio de la 
pintura y la contemplación. El suyo fue un trayecto exitoso y enaltecedor. El insecto resultante es emblema de triunfo y de conocimiento. Hay que subrayar que, si bien hay en estos cuentos de Eunice un hálito espiritual, no se aprecia una visión cristiana tradicional, vinculada con la devoción, y ni siquiera se menciona una entidad divina aunque sí una dimensión trascendente, "la integración de mi ser, infinitamente pequeño, en el Todo, infinitamente grande" (p. 282).

En el segundo relato de Odio aflora por boca del personaje científico todo un vocabulario relativo al ADN, división celular, ARN, ribosomas, etc., para de esta manera apuntalar por vía materialista la aspiración del personaje por atrapar el mecanismo de la vida. Este mismo recurso se usa en el cuento de una narradora costarricense posterior, de origen chileno, Myriam Bustos Arratia, titulado "Mutante", y contenido en su libro El regreso de O.R. (1993). Si bien lo fantástico ha sido ocasional en su escritura, este relato es una buena muestra de su incursión en este campo, en donde también se apoya en la ciencia para dar verosimilitud a su historia. A diferencia de la inspiración metafísica de Eunice Odio, en Myriam Bustos lo fantástico se produce sobre una base científica, y el mismo título, "Mutante", apunta a ello, pues podría decirse que la mutación es una metamorfosis natural, impulsada por la propia genética. Además, su perspectiva es materialista y asentada en el cuerpo, de una sutil ironía, enfocada, más que en su transformación, en su decadencia, con un claro sentido de la enfermedad y la muerte.

En su cuento, la mutación es el proceso "monstrificador" del sujeto, en ese caso, una mujer, cuando descubre una metamorfosis en su genitalia, pues ahí crece "una especie vegetal única e inclasificable" (Bustos-Arratia, 1993, p. 43), una especie de planta donde antes tenía su órgano femenino, comparada con una lechuga, una acelga y, sobre todo, un brócoli. La visita a los ginecólogos la confirma en su posición de que, aunque el fenómeno es insólito,

no lo hallaba tan anormal, puesto que todas las especies del mundo orgánico ha ido cambiando y
adaptándose a las nuevas condiciones del medio, además de que la constitución celular entre ellas
coincide en distintos seres vivos pertenecientes a reinos disímiles. Solo que en este caso, se trataba de la
mutación de un solo órgano de un solo ser humano. (Bustos-Arratia, 1993, pp. 42-43)

La voz narrativa afirma que:

\begin{abstract}
Casi podía decirse que un nuevo individuo - de seguro vegetal- estaba naciendo y desarrollándose en hábitat tan ajeno a su condición y materia, suplantando ya del todo al órgano que antes en nada se distinguía del que identificaba a cualquier mujer. [...] Hojas diríase que habían emergido. O pétalos. O brácteas, tal vez. Pero transcurridos los días sufrían nuevas mutaciones y semejaban inflorescencias o apretados racimos de textura granulosa. (Bustos-Arratia, 1993, p. 42)
\end{abstract}

No es un organismo completo el que se vuelve monstruoso sino apenas una de sus partes, una muy importante y simbólica, es cierto, y en esta medida el carácter teratológico se irradia a todo el cuerpo. Se trata, sin embargo, de un monstruo íntimo, que puede ser cubierto por el secreto, pues de él sólo saben ella, los médicos que la han tratado y su marido, "un extraño híbrido de científico y vegetariano" que, lejos de asustarse con lo que le pasa a su mujer, se intriga como en un caso más de rara biología, y que, hacia el final del cuento, se apresta a realizar con el nuevo órgano de su mujer una suerte de canibalismo vegetariano. La tranquilidad de los personajes ante lo que ocurre contribuye a crear un ambiente más extraño que fantástico, como con el insecto de Kafka, que todo mundo parece aceptar sin asombro, solo que en Bustos el secreto monstruoso se mantiene al interior de un pequeño grupo. En ella, mediante la ironía, el poder numinoso del monstruo ha llegado casi al grado cero, pues no produce terror sino apenas curiosidad y apetito. 


\section{Herra y el monstruo prodigioso}

No quisiera acabar esta trayectoria de lectura de monstruos nacionales sin mencionar el caso de Rafael Ángel Herra, un escritor que ha hecho del monstruo uno de los puntos centrales de su meditación y de su escritura, como puede apreciarse en dos libros que, vistos desde la crítica, se complementan muy bien: la novela La guerra prodigiosa (1986) y su compañero teórico, el libro de ensayos titulado Lo monstruoso y lo bello (1988), en donde analiza, entre otros textos, "La transformación" de Kafka. Herra pertenece a un pequeño grupo de escritores que son, al mismo tiempo, filósofos de profesión, con lo que su obra literaria suele alimentarse de problemas enraizados en difíciles asuntos intelectuales, que adquieren una expresión literaria. Su formación en las filosofías alemana y francesa, la fenomenología y el existencialismo, marca su obra con ciertas preocupaciones, entre éstas, la guerra, la violencia y el monstruo.

En cuanto a este último, Herra se adhiere a la visión moderna y secular, influida por el psicoanálisis, que ve al monstruo, no como una creación exterior a su creador, menos como algo con existencia propia, sino como una suerte de proyección, “de conjurar por expulsión lo más íntimo que el ser integra" (Herra, 1988, p. 11). En palabras de Néstor Braunstein, en el prólogo que antecede al ensayo de Herra, los monstruos

\footnotetext{
son creados más o menos de modo preconsciente por los artistas, por los poetas, por los que aplacan sus demonios interiores mediante la creación significante en una tarea que la doctrina (psicoanalítica) recoge con el nombre de sublimación. Gólemes, sosias, personificaciones del mal, códigos genéticos, invenciones químicas o cerebros artificiales desbocados, sidas e invasores extraterrestres, infinitas variaciones del arte de divertir asustando, de subordinar lo siniestro a las leyes de la poesía, de encuadrarlo dentro de una ley, de fingir que lo fabricado, el sujeto, es lo fabricante. (Herra, 1988, pp. 12-13)
}

El tratamiento que Herra hace del monstruo impide encasillarlo como un asunto solo fantástico, sino que irradia a otras zonas del pensamiento y la creación. Así, en la novela La guerra prodigiosa aparece una diversidad de entes monstruosos, pero mal se haría en clasificar a dicho texto como "fantástico", pues se trata más bien de un relato fabuloso y alegórico con vocación de ensayo, ubicado en los primeros siglos de nuestra era, con anacoretas errantes que se enfrentan en su lucha ética y filosófica con toda suerte de alimañas, incluido por supuesto el mismo diablo.

$\mathrm{Y}$ ya que se abrió este texto mencionando las sirenas iniciales en la literatura costarricense, las de Argüello y García Monge, clausurémosla con las sirenas que aparecen en el texto de Herra, como cerrando un círculo de lectura. Se trata de las dos sirenas ciegas con las que se tiene que enfrentar el santo errante de su novela, en el capítulo XXXI, las que "reposaban frente a frente, reinando sobre los viajeros desde sus vastos imperios de oscuridad", sirenas que tienen algo de Medusa, pues petrificaban a los forasteros que no respondían a sus preguntas, y que son descritas con "cuerpos de pájaro, brillantes como incandescencias inmortales bajo el sol y pálidos como estrellas terrestres por la noche", y que "embriagaban al forastero, quien se ahogaba entonces en charcos de amarga miel y sensaciones equívocas" (Herra, 1986, p. 174). Poseen garras, cabelleras negras que serpentean en el aire, ojos inmóviles que son "vestigios de inmortalidad".

A su pregunta sobre cuál de ellas era la más poderosa, el anacoreta responde que la que "doblegue a la adversaria con sus ojos muertos", y mientras las sirenas se miran sin verse y buscan en vano a la otra, él se escapa de su dominio. Su astucia ha prevalecido sobre el poder ciego. Como puede apreciarse, aquí la sirena conjunta tanto los poderes pétreos de la Gorgona, como los enigmas de la esfinge, solo para ser vencida por partida doble. 
Solamente queda reconocer cuánto creció nuestro monstruo seminal, la sirena, campirana en los primeros tiempos, los de Argüello y García Monge, hasta convertirse en esta sofisticada sirena ciega de Rafael Ángel Herra. Una muestra de las metamorfosis incesantes del monstruo en la literatura costarricense a lo largo de un siglo, y que sigue mostrando otros rostros en nuevos autores.

\section{Bibliografía}

Argüello-Mora, M. (2012). La poza de la Sirena. Por J. R. Chaves (Ed.). Voces de la Sirena. Antología de literatura fantástica de Costa Rica. (23-31). San José: Uruk.

Borges, J. L., Bioy-Cásares, A. y Ocampo, S. (1976). Antología de la literatura fantástica. Buenos Aires: Editorial Sudamericana.

Bustos-Arratia, M. (1993). El regreso de O.R. San José: EUNED.

Cardona, J. (2012). La caja del doctor (cuento macabro). Por J. R. Chaves (Ed.). Voces de la Sirena Antología de literatura fantástica de Costa Rica. (35-45). San José: Uruk.

Cardona-Peña, A. (1980). Los ojos del cíclope. México: Diana.

Cardona-Peña, A. (2012). El brebaje. Por J. R. Chaves (Ed.). Voces de la Sirena Antología de literatura fantástica de Costa Rica. (223-224). San José: Uruk.

Castillo-Víquez, A. E. (2004). Una construcción femenina particular: la imagen de la sirena en los textos de Carlos Gagini. Káñina, Rev. Artes y Letras. 28 (2), 21-34.

Fernández-Guardia, R. (2004). Hojarasca. San José: EUNED.

García-Monge, J. (2009). Cuyeos y majafierros y otros cuentos. F. Herrera (Ed. y Comp.). San José: EUNED.

Herra, R. Á. (1986). La guerra prodigiosa. San José: Editorial Costa Rica.

Herra, R. Á. (1988). Lo monstruoso y lo bello. San José: Editorial de la Universidad de Costa Rica.

Monterroso, A. (1991). La literatura fantástica en México. El relato fantástico en España e Hispanoamérica. Madrid: Sociedad Estatal Quinto Centenario.

Odio, E. (1996). Obras completas. P. Von-Mayer (Ed.). San José: EUCR/EUNA. 
